\title{
Patent Foramen Ovale and Cryptogenic Stroke or Transient Ischemic Attack: To Close or Not to Close? A Systematic Review and Meta-Analysis
}

\author{
Simona Lattanzi ${ }^{a}$ Francesco Brigo $^{\text {b, c }}$ Claudia Cagnettia ${ }^{a}$ Mario Di Napoli ${ }^{d, e}$ \\ Mauro Silvestrini ${ }^{a}$ \\ ${ }^{a}$ Department of Experimental and Clinical Medicine, Neurological Clinic, Marche Polytechnic University, Ancona, \\ Italy; ${ }^{b}$ Department of Neuroscience, Biomedicine and Movement Science, University of Verona, Verona, Italy;

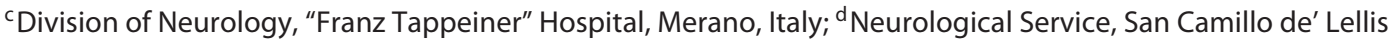

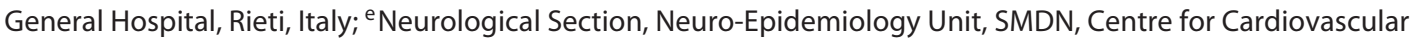 \\ Medicine and Cerebrovascular Disease Prevention, L'Aquila, Italy
}

\section{Keywords}

Cryptogenic stroke $\cdot$ Patent foramen ovale $\cdot$ Meta-analysis

\begin{abstract}
Background: The optimal strategy of secondary stroke prevention in patients with patent foramen ovale (PFO) is controversial. This study was performed to evaluate the efficacy and safety of the device closure (DC) versus the medical therapy (MT) in patients with cryptogenic stroke or transient ischemic attack (TIA) and PFO. Summary: Randomized controlled trials with active and control groups receiving the DC plus MT and MT alone in patients with history of cryptogenic stroke/TIA and diagnosis of PFO were systematically searched. The main efficacy outcome was stroke recurrence. Subgroup-analyses were performed according to age, shunt size, and presence of atrial septal aneurysm (ASA). Safety endpoints included any serious adverse event (SAE), atrial
\end{abstract}

fibrillation (AF), and major bleeding complications. Risk ratios (RRs) and hazard ratios (HRs) with 95\% Cls were estimated. Five trials were included, involving 3,440 participants ( $D C=1,829, M T=1,611)$. There was a protective effect of closure in the risk of recurrent stroke (RR 0.43 [0.21-0.90]; $p=0.024 ; \mathrm{HR}=0.39$ [0.19-0.83]; $p=0.014$ ). The benefit of PFO closure was significant in patients with PFO associated with substantial right-to-left shunt or ASA. There were no differences in the risks of SAEs and major bleedings between the groups. The rate of new-onset AF was higher in the DC than in the MT arm (RR 4.46 [2.35-8.41]; $p<0.001)$. Successful device implantation and effective PFO closure were achieved in 96 and $91 \%$ of the patients respectively. Key Messages: In selected adult patients with PFO and history of cryptogenic stroke, the DC plus MT is more effective to prevent stroke recurrence and is associated with an increased risk of new-onset AF compared to the MT alone.

(c) 2018 S. Karger AG, Basel

\section{KARGER}

(c) 2018 S. Karger AG, Basel

E-Mail karger@karger.com

www.karger.com/ced
Simona Lattanzi

Department of Experimental and Clinical Medicine, Neurological Clinic

Marche Polytechnic University

Via Conca 71, IT-60020 Ancona (Italy)

E-Mail alfierelattanzisimona@gmail.com 


\section{Introduction}

Acute cerebrovascular disease is among the leading causes of mortality and disability worldwide $[1,2]$. More than two thirds of all strokes are ischemic, and $25-40 \%$ of these are classified as cryptogenic, since no underlying cause can be identified despite extensive diagnostic workup $[3,4]$.

Patent foramen ovale (PFO) is an embryonic defect of the inter-atrial septum, which can be found in approximately $25 \%$ of healthy adult population $[5,6]$. The PFO has been associated with an increased risk of cerebral ischemia, and evidence for this association is mostly driven by epidemiologic data. Several case-controls studies have shown that $\mathrm{PFO}$ is detected more frequently in young adults $(<55$ years-old) with cryptogenic stroke than in control subjects without stroke or patients with stroke of known cause [7, 8]. This association appears to be stronger when PFO is accompanied by an atrial septal aneurysm (ASA) and/or in the presence of a large shunt size [8-10].

The pathophysiology of stroke in patients with PFO may be multifactorial. Paradoxical embolism, which refers to the passage of a thrombus of venous origin into the systemic arterial circulation, is the most invoked mechanism. Other potential sources include intra-cardiac clots deriving from arrhythmias, which may develop in association with PFO or ASA $[11,12]$, or thrombosis in-situ at the level of the foramen channel or ASA [13, 14]; thrombotic or pre-thrombotic conditions may act as cofactors [15]. The optimal strategy of secondary stroke prevention, which may comprise the endovascular PFO closure and the anti-thrombotic therapy, remains still debated. In this regard, new findings from randomized clinical trials have been recently reported, calling for a critical reappraisal of the available evidence.

The aim of the current study was to evaluate the efficacy and safety of the trans-catheter device closure (DC) associated with the medical therapy (MT) compared to the MT alone in patients with history of cryptogenic ischemic stroke or transient ischemic attack (TIA) and diagnosis of PFO, through a systematic review and meta-analysis of the currently available randomised controlled trials.

\section{Materials and Methods}

\section{Search Strategy}

The study results were reported according to the recommendations of the Preferred Reporting Items for Systematic Reviews and Meta-Analyses statement [16]. We systematically searched (December week 1, 2017) MEDLINE (accessed through PubMed),
CENTRAL (Cochrane Central Register of Controlled Trials) and the US National Institutes of Health Clinical Trials Registry (http:// www.clinicaltrials.gov; online suppl. Appendix 1; for all online suppl. material, see www.karger.com/doi/10.1159/000488401). There were no date limitations or language restrictions. The reference lists of retrieved studies were reviewed to search for additional reports of relevant trials. The review protocol has been registered in the International prospective register of systematic reviews (PROSPERO; CRD42018084166).

\section{Eligibility Criteria}

Studies were selected when they met the following inclusion criteria: randomized, controlled trials, with active and control groups receiving trans-catheter DC (regardless of device type) of PFO plus MT and the MT (defined as any antiplatelet and/or anticoagulant agent) alone respectively. Participants had to meet the following criteria: any gender, any ethnicity, adult age, with a history of cryptogenic stroke or TIA, and a diagnosis of PFO.

\section{Outcome Measures}

Efficacy endpoints were the occurrence of ischemic stroke, TIA and composite outcome events. Since the unavailability of standardized criteria for the composite outcome, the trial-specific definitions were used (online suppl. Table 1). Safety endpoints included the occurrence of any serious adverse event (SAE), atrial fibrillation (AF) or flutter, and major bleeding complications. All-cause mortality, success of device implantation (defined as successful implantation of one or more closure devices during the index procedure, with no procedural complications), and success of PFO closure (defined as closure with no or trace residual shunt on transesophageal echocardiography) were also considered.

\section{Study Selection, Data Extraction, and Assessment of the Risk} of Bias

Two review authors (S.L. and C.C.) independently assessed trials for inclusion and extracted the information from the included trials. Any disagreement was resolved by a discussion with a third review author (M.S.).

The risk of bias of the identified studies was assessed in accordance with the recommendations of the Cochrane Collaboration [17]. Funnel plots and Egger statistical test were used to evaluate the publication bias risk.

\section{Statistical Analysis}

Heterogeneity among the trials was assessed by the chi squared test and the $\mathrm{I}^{2}$ statistics for heterogeneity [17-19]. When no significant heterogeneity was present $(p>0.10)$, results were synthesized using a fixed effect model; if the probability value was $\leq 0.10$, heterogeneity determined the choice of a fixed- or random effects model for $\mathrm{I}^{2}<40$ or $\geq 40 \%$, respectively [20-23]. The inverse variance method was used and risk estimates synthesized by the risk ratio (RR) for the dichotomous outcomes; time-to-event outcomes were pooled with the generic inverse variance (logarithm of the risk estimate and its standard error), yielding results as hazard ratios (HRs). The intent-to-treat population data were used for all the analyses. Subgroup analyses were defined in advance to investigate the potential heterogeneity of the treatment effect in preventing recurrent strokes according to the following baseline covariates, as suggested to be potentially related to the development 
Fig. 1. Flow diagram of the identification and selection of eligible studies.

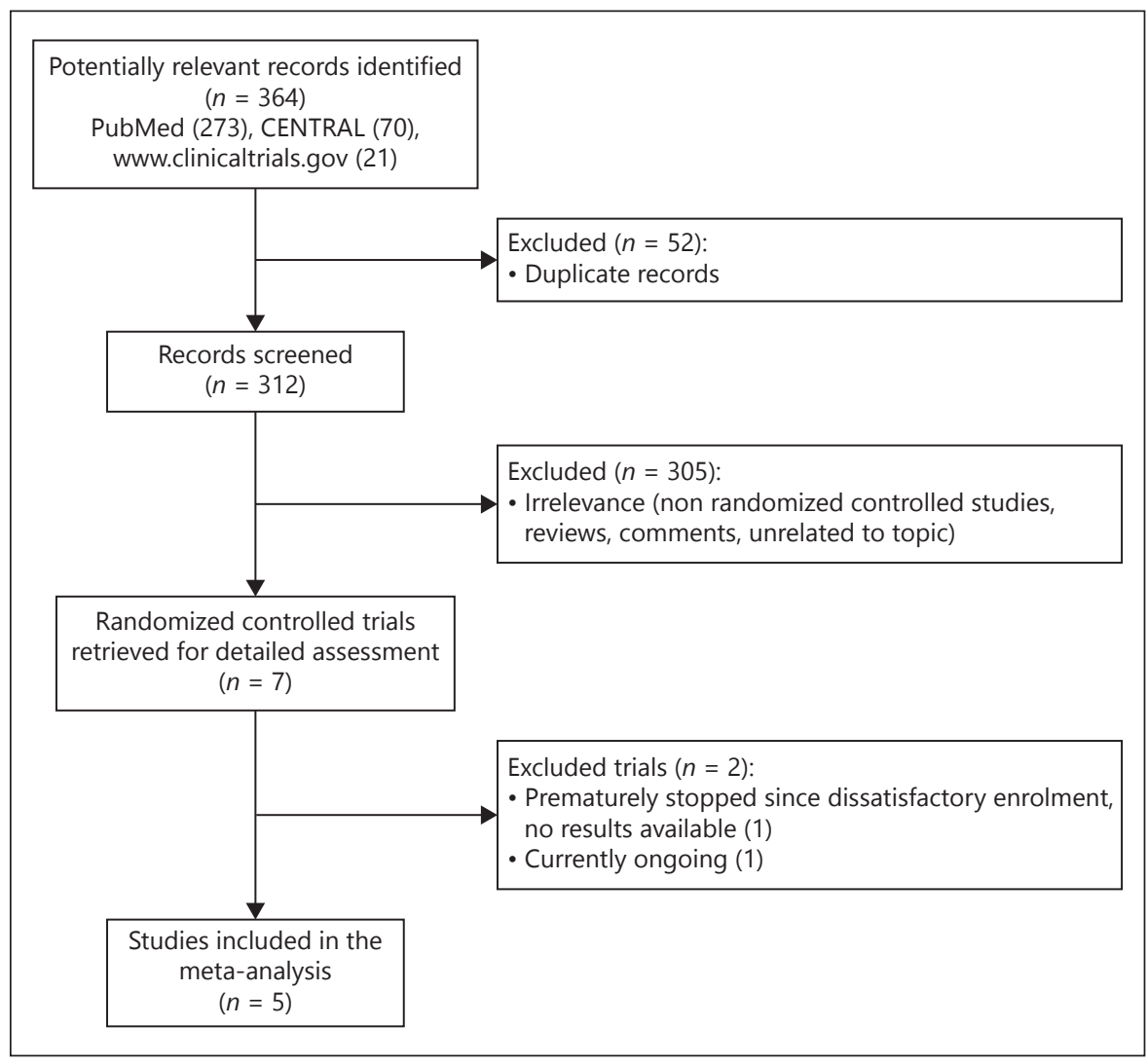

of vascular outcome $[6,24,25]$ : age (younger versus older), PFO shunt size (substantial versus not substantial), and ASA (presence versus absence). Reported probability values were 2 -side, with significance set at $<0.05$. Data analysis was performed using STATA/ IC 13.1 statistical package (StataCorp LP, College Station, TX, USA).

\section{Results}

\section{Results of the Search}

Three hundred and sixty-four records were found by searching databases and trial registers. Seven randomized controlled trials [26-32] were identified, of which 2 were excluded from the qualitative and quantitative syntheses: the Effect of DC of PFO in Elderly Patients With Cryptogenic Stoke/TCI (CryptoCard) study [26] was prematurely terminated due to the dissatisfactory enrollment rate with no publication provided, and the DC versus MT for Cryptogenic Stroke Patients with High-Risk PFO (DEFENSE-PFO) [27] was still ongoing. Accordingly, a total of 5 trials [28-32] were included in the review and meta-analysis (Fig. 1).

PFO and Cryptogenic Stroke or TIA

\section{Characteristics and Risk of Bias of Included Studies}

Characteristics of the studies with main inclusion and exclusion criteria are provided in online supplementary Table 2. Different devices were used across the trials: the NMT Medical STARFlex in the CLOSURE I, the St. Jude Amplatzer septal occluder in the PC and RESPECT, the Gore Helex septal occluder/Cardioform septal occluder in the Gore REDUCE. In the CLOSE study, any CE-marked device was allowed and among the 11 different devices used, the St. Jude Amplatzer device was the most common (51.5\%). In the MT group, anti-thrombotic treatment was left at the discretion of the treating physician in the CLOSURE I, PC and RESPECT trials. The CLOSE study compared either PFO closure or oral anticoagulation with antiplatelet therapy: the pre-specified pooled analysis of patients randomized to DC or antiplatelet therapy was reported. In the REDUCE trial, all patients received antiplatelet therapy, which could consist of aspirin, aspirin plus dipyridamole, or clopidogrel chosen by the local investigator at each participating site. Details of type and duration of treatments are described in Table 1.

All included trials were randomized, open-label, and outcome-blinded. They were rated as high risk of perfor- 
Table 1. Treatments across individual trials

\begin{tabular}{|c|c|c|}
\hline CLOSURE I [28] & $\begin{array}{l}\text { STARFlex device + clopidogrel } 75 \mathrm{mg} / \text { day } \\
\text { (6 months) and aspirin } 81-325 \mathrm{mg} / \text { day ( } 2 \text { years })\end{array}$ & $\begin{array}{l}\text { Aspirin } 325 \mathrm{mg} / \text { day, warfarin (target } \\
\text { international normalized ratio } 2.0-3.0 \text { ), or both } \\
\text { (at the discretion of the principal investigator at } \\
\text { each site) }\end{array}$ \\
\hline PC [29] & $\begin{array}{l}\text { Amplatzer PFO occluder + aspirin } 100-325 \mathrm{mg} / \text { day (for } \\
\text { at least } 5-6 \mathrm{months} \text { ) and ticlopidine } 250-500 \mathrm{mg} \text { /day or } \\
\text { clopidogrel } 75-150 \mathrm{mg} / \text { day ( } 1-6 \text { months) }\end{array}$ & $\begin{array}{l}\text { Antiplatelet therapy or oral anticoagulation (at } \\
\text { the discretion of the treating physician) }\end{array}$ \\
\hline RESPECT [30] & $\begin{array}{l}\text { Amplatzer PFO occluder }+ \text { aspirin } 81-325 \mathrm{mg} / \text { day and } \\
\text { clopidogrel ( } 1 \text { month), followed by aspirin monotherapy } \\
\text { ( } 5 \text { months). Subsequently, anti-thrombotic therapy at the } \\
\text { discretion of the site investigator }\end{array}$ & $\begin{array}{l}\text { Aspirin, warfarin, clopidogrel, aspirin + } \\
\text { extended-release dipyridamole, aspirin }+ \\
\text { clopidogrel (up to 2006) }\end{array}$ \\
\hline Gore REDUCE [32] & $\begin{array}{l}\text { Helex septal occluder (through late } 2012 \text { ) or cardioform } \\
\text { septal occluder (from late } 2012 \text { onward) and one } 300-\mathrm{mg} \\
\text { dose of clopidogrel before or immediately after the } \\
\text { procedure (if not already taken) + clopidogrel } 75 \mathrm{mg} / \text { day } \\
\text { ( } 3 \text { days), followed by aspirin } 75-325 \mathrm{mg} / \text { day, aspirin } \\
50-100 \mathrm{mg} / \text { day combined with dipyridamole } \\
225-400 \mathrm{mg} \text { /day, or clopidogrel } 75 \mathrm{mg} / \text { day }\end{array}$ & $\begin{array}{l}\text { Aspirin } 75-325 \mathrm{mg} / \text { day, aspirin } 50-100 \mathrm{mg} / \text { day } \\
\text { combined with dipyridamole } 225-400 \mathrm{mg} \text { day, } \\
\text { or clopidogrel } 75 \mathrm{mg} / \text { day }\end{array}$ \\
\hline
\end{tabular}

mance bias since participants and personnel knew the assigned treatment and low risk of detection bias, since endpoint events were adjudicated by independent committees, whose members were unaware of the treatment assignments. Although the number of patients who withdrew from the study or were lost to follow-up were clearly reported and the intent-to-treat analyses performed in the PC, RESPECT, and Gore REDUCE trials, the high dropout rate compared with the event rate and the difference in the dropout rate between the 2 arms could lead to the risk of attrition bias. Selective reporting bias was introduced in the PC trial because the adjudication committee discounted potential primary endpoint events more often in the MT than in the DC group. The summary of the risks of bias is shown in online supplementary Table 3. The funnel plots and Egger's tests did not suggest evidence of publication bias (online suppl. Appendix II).

\section{Characteristics of Study Participants}

The studies included 3,440 participants, 1,829 and 1,611 randomized to DC and MT respectively. Demographics and cardiovascular risk factors were similar be- tween treatment groups within each trial (Table 2). The proportion of patients with large inter-atrial shunt size was higher in the CLOSE, RESPECT, and REDUCE compared to the CLOSURE I and PC trials. The mean follow-up varied across the studies and ranged from 2 years in the CLOSURE I to 5.9 years in the Gore RESPECT; however, in all studies the risk estimates were also presented as HRs, which account for time-toevent.

\section{Efficacy Outcomes}

Overall, there were 109 recurrent strokes, 37 out of $1,829(2.0 \%)$ in the DC group and 72 out of $1,611(4.5 \%)$ in the MT group. The RR for recurrent stroke was 0.43 (95\% CI 0.21-0.90; $p=0.024)$ in favor of the PFO closure (Fig. 2a); similarly, the pooled HR indicated a statistically significant protective effect of closure in comparison to the MT (HR 0.39 [95\% CI 0.19-0.83]; $p=0.014$; chi squared $=9.30$, degrees of freedom $(\mathrm{df})=4, p=0.054 ; \mathrm{I}^{2}=$ $57.0 \%)$. Four trials reported the number of TIAs during the follow-up. A total of 98 events occurred with 43 (3.1\%) in the PFO closure versus 55 (4.0\%) in the MT group. The 
Table 2. Characteristics of study participants

\begin{tabular}{|c|c|c|c|c|c|c|c|c|c|c|c|}
\hline Study [reference] & Arm & $\begin{array}{l}\text { Patients, } \\
n\end{array}$ & Men, $\%$ & $\begin{array}{l}\text { Age, years, } \\
\text { mean }\end{array}$ & HTN, \% & $\mathrm{DM}, \%$ & HLP, \% & Smoking, \% & $\begin{array}{l}\text { Substantial } \\
\text { shunt }\end{array}$ & ASA & $\begin{array}{l}\text { Follow-up length, } \\
\text { years }\end{array}$ \\
\hline CLOSURE I [28] & DC & 447 & 52.1 & $46.3 \pm 9.6$ & 33.8 & - & 47.4 & 21.5 & $55.9^{*}$ & 37.6 & 2.0 \\
\hline \multirow[t]{2}{*}{ PC [29] } & DC & 204 & 45.1 & $44.3 \pm 10.2$ & 24.0 & 2.5 & 24.5 & 25.5 & 23.2 & 23.0 & 4.1 \\
\hline & MT & 210 & 54.3 & $44.6 \pm 10.1$ & 27.6 & 2.9 & 29.5 & 22.4 & 20.1 & 24.3 & 4.0 \\
\hline \multirow[t]{2}{*}{ CLOSE [31] } & DC & 238 & 57.6 & $42.9 \pm 10.1$ & 11.3 & 1.3 & 12.6 & 28.6 & 90.8 & 34.0 & $5.4 \pm 1.9$ \\
\hline & $\mathrm{MT}^{\dagger}$ & 235 & 60.4 & $43.8 \pm 10.5$ & 10.2 & 3.8 & 15.3 & 29.4 & 94.9 & 31.5 & $5.2 \pm 2.1$ \\
\hline \multirow[t]{2}{*}{ Gore REDUCE [32] } & DC & 441 & 59.2 & $45.4 \pm 9.3$ & 25.4 & 4.1 & - & 14.3 & 42.8 & 20.4 & 3.2 (IQR 2.2-4.8) \\
\hline & MT & 223 & 61.9 & $44.8 \pm 9.6$ & 26.0 & 4.5 & - & 11.3 & 36.6 & - & \\
\hline
\end{tabular}

* Moderate or substantial shunt.

${ }^{\dagger}$ Antiplatelet-only group.

ASA, atrial septal aneurysm; DC, device closure; DM, diabetes mellitus; HLP, hyperlipidemia; HTN, hypertension; IQR, interquartile range; MT, medical therapy.

pooled effect-estimate RR (0.78 [95\% CI 0.53-1.15]; $p=$ 0.213; Fig. 2b) and HR (0.73 [95\% CI 0.49-1.09]; $p=$ 0.124 ; chi squared $\left.=0.51, \mathrm{df}=3, p=0.917 ; \mathrm{I}^{2}=0.0 \%\right)$ did not show significant differences between the treatment arms. Composite outcome events occurred in $78(4.3 \%)$ and $109(6.8 \%)$ patients randomized to the DC and MT respectively: the pooled RR $(0.62$ [95\% CI $0.46-0.82] ; p=$ 0.001; Fig. 2c) and HR (0.58 [95\% CI 0.43-0.77]; $p<0.001$; chi squared $\left.=2.28, \mathrm{df}=4, p=0.685 ; \mathrm{I}^{2}=0.0 \%\right)$ demonstrated a beneficial effect of the PFO closure.

\section{Safety Outcomes}

There were no statistically meaningful differences in the risks of SAEs (RR 1.04 [95\% CI 0.93-1.16]; $p=0.475$ ) and major bleedings (RR 1.00 [95\% CI 0.53-1.90]; $p=$ $0.997)$ across the study arms. Conversely, new-onset AF or flutter was significantly more common in patients randomized to the DC (4.3\%) compared to the MT $(0.7 \%$; RR 4.45 [95\% CI 2.35-8.41]; $p<0.001$; Fig. 3). Overall, 28 deaths occurred, 13 in the DC and 15 in the MT groups: the mortality rate was not significantly different across the treatments (RR 0.74 [95\% CI 0.35-1.60]; $p=$ 0.448).

Device implantation was successful in $95.6 \%$ of the patients: the lowest rate was found in the CLOSURE I (89.4\%) and the highest in the CLOSE (99.6\%) trials. Effective closure was achieved in $91.4 \%$ of the participants: the lowest (86.1\%) and the highest (96.0\%) rates were observed in the CLOSURE I and PC studies respectively.

\section{Subgroup Analyses}

There was no significant treatment-effect heterogeneity in the reduction of stroke risk in the DC compared to the MT according to younger (RR 0.39 [95\% CI $0.18-$ 0.84 ]; $p=0.016$ ) and older (RR 0.48 [95\% CI 0.26-0.90]; $p=0.021$ ) age (test for sub-groups difference: chi squared $=0.21, \mathrm{df}=1, p=0.650$; Fig. $4 \mathrm{a}$ ). Younger versus older age groups were defined according to the threshold of 45 years in the RESPECT and REDUCE trials and 44.6 years in the CLOSE study. Conversely, the benefit of the PFO closure compared with the MT was significantly greater in patients with substantial (RR 0.23 [95\% CI 0.11-0.48]; $p<0.001)$ than among those with not substantial (RR 0.94 [95\% CI 0.46-1.95]; $p=0.874$ ) right-to-left shunt (test for sub-groups difference: chi squared $=7.12$, $\mathrm{df}=1, p=0.008$; Fig. $4 \mathrm{~b}$ ). Substantial shunt was defined by the appearance of more than 20 $[29,30], 25[28,32]$, or 30 [31] microbubbles in the left atrium within 3 [29-32] or 5 [28] cardiac cycles after opacification of the right atrium. A trend toward greater efficacy of the DC strategy was observed in patients with ASA (RR 0.17 [95\% CI 0.06-0.53]; $p=0.002$ ) than among those without ASA (RR 0.85 [95\% CI 0.43-1.68]; $p=$ 0.648 ; test for sub-groups difference: chi squared $=5.66$, $\mathrm{df}=1, p=0.017$; Fig. $4 \mathrm{c})$. ASA was defined as a septum primum excursion of $10 \mathrm{~mm}$ or greater $(15 \mathrm{~mm}$ or greater in the PC trial [29]), as identified on transesophageal echocardiography. 


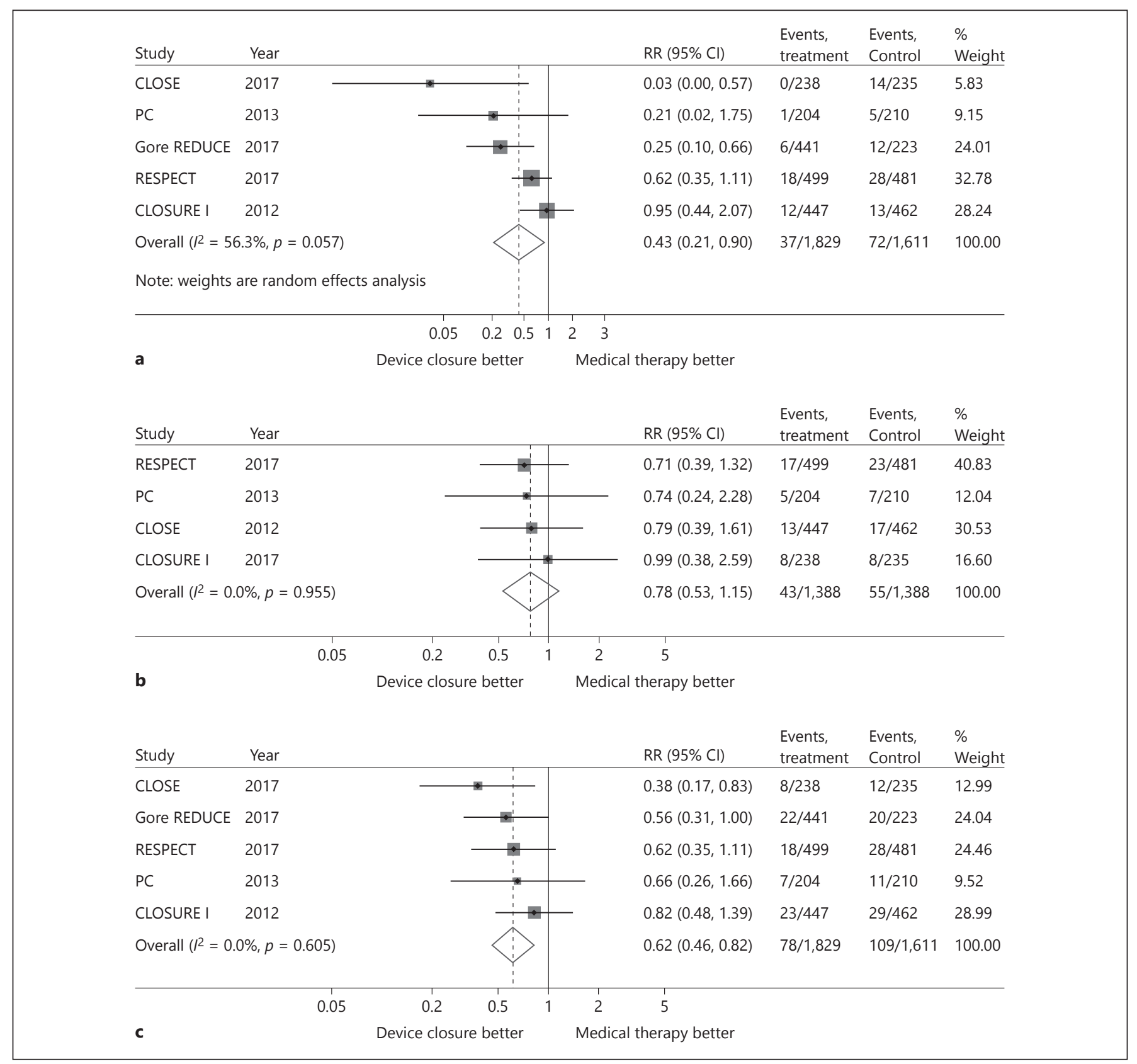

Fig. 2. Efficacy of the device closure versus the medical therapy. a Stroke. b Transient ischemic attack. c Composite outcome.

\section{Discussion}

Thecurrent meta-analysis of 5 multicenter, randomized, controlled trials indicates that in adult patients younger than 60 years and who were found to have a PFO in the setting of a cryptogenic ischemic stroke or TIA, the percutaneous trans-catheter closure associated to the MT can be more effective than the MT alone to prevent stroke recurrence.
Compared to the conservative strategy, the DC was associated with an approximately $60 \%$ reduction in the risk of stroke: although the annual stroke risk is overall low and the absolute reduction with the PFO closure is modest, cumulative lifetime benefit is likely meaningful. The benefit of the $\mathrm{DC}$ was primarily seen in patients with $\mathrm{PFO}$ and substantial inter-atrial shunt, while there was no clear evidence of superiority over the MT in the absence of 


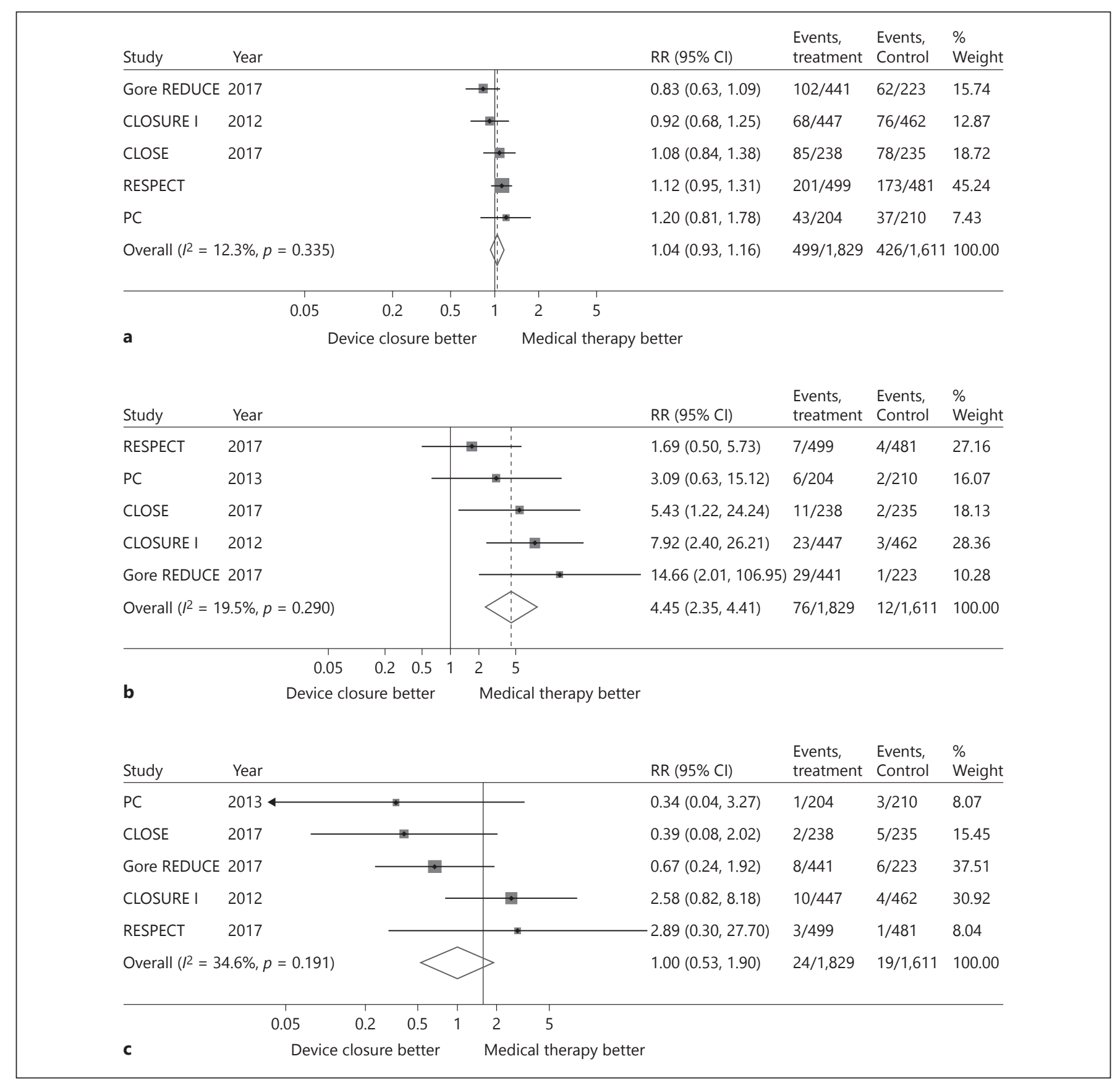

Fig. 3. Safety of the device closure versus the medical therapy. a Any serious adverse event. b Atrial fibrillation or flutter. c Major bleeding.

such feature. Potential heterogeneity of the treatment effect was also observed according to the presence of the ASA, with a greater reduction of stroke risk in patients with a PFO-associated ASA than among those without a PFO-associated ASA. Conversely, age did not influence the benefit of the endovascular strategy, which persisted in patients in their late 40 s and 50s. The DC was associ- ated with a lower rate of composite outcome events: since there is a similar incidence of TIAs and deaths across the arms, it is reasonable to mainly interpret this finding as the effect in the reduction of stroke recurrence.

Since PFO has a high prevalence and the potential benefit from closure depends on individual clinical characteristics, the comprehensive multidisciplinary assessment 


\begin{tabular}{|c|c|c|c|c|c|c|c|c|}
\hline Study & Year & & & & $\mathrm{RR}(95 \% \mathrm{Cl})$ & $\begin{array}{l}\text { Events, } \\
\text { treatment }\end{array}$ & $\begin{array}{l}\text { Events, } \\
\text { Control }\end{array}$ & $\begin{array}{l}\% \\
\text { Weight }\end{array}$ \\
\hline \multicolumn{9}{|l|}{ Younger } \\
\hline CLOSE & 2017 & $\longrightarrow$ & & & $0.08(0.00,1.47)$ & $0 / 124$ & $5 / 112$ & 2.79 \\
\hline Gore REDUCE & 2017 & (5) & & & $0.28(0.07,1.10)$ & $3 / 204$ & $6 / 114$ & 12.42 \\
\hline RESPECT & 2017 & & & & $0.55(0.20,1.48)$ & $6 / 230$ & $10 / 210$ & 23.46 \\
\hline \multicolumn{3}{|c|}{ Subtotal $\left(R^{2}=0.0 \%, p=0.407\right)$} & & & $2.38(0.18,0.84)$ & $9 / 558$ & $21 / 436$ & 38.68 \\
\hline \multicolumn{9}{|l|}{ Older } \\
\hline CLOSE & 2017 & $\longrightarrow$ & & & $0.06(0.00,0.96)$ & $0 / 114$ & 9/123 & 2.89 \\
\hline Gore REDUCE & 2017 & 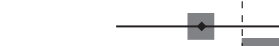 & & & $0.23(0.06,0.90)$ & $3 / 237$ & $6 / 109$ & 12.42 \\
\hline RESPECT & 2017 & & & & $0.68(0.33,1.38)$ & $12 / 262$ & $18 / 266$ & 46.01 \\
\hline \multicolumn{3}{|c|}{ Subtotal $\left(R^{2}=52.3 \%, p=0.123\right)$} & & & $0.48(0.26,0.90)$ & $15 / 613$ & $33 / 498$ & 61.32 \\
\hline \multicolumn{9}{|c|}{ Heterogeneity between groups: $p=0.650$} \\
\hline \multicolumn{3}{|c|}{ Overall $\left(I^{2}=19.3 \%, p=0.288\right)$} & & & $0.44(0.27,0.72)$ & $24 / 1,171$ & $54 / 934$ & 100.00 \\
\hline \multirow{2}{*}{\multicolumn{2}{|c|}{ a }} & $\begin{array}{lll}0.05 & 0.2 & 0.5\end{array}$ & 2 & 5 & & \multirow[b]{3}{*}{$\begin{array}{l}\text { Events, } \\
\text { treatment }\end{array}$} & \multirow[b]{3}{*}{$\begin{array}{l}\text { Events, } \\
\text { Control }\end{array}$} & \multirow[b]{3}{*}{$\begin{array}{l}\% \\
\text { Weight }\end{array}$} \\
\hline & & \multicolumn{4}{|c|}{ Device closure better Medical therapy better } & & & \\
\hline Study & Year & & & & $\mathrm{RR}(95 \% \mathrm{Cl})$ & & & \\
\hline \multicolumn{9}{|l|}{ Subtantial } \\
\hline Gore REDUCE & 2017 & & & & $0.20(0.06,0.62)$ & $4 / 348$ & $10 / 173$ & 20.09 \\
\hline RESPECT & 2017 & & & & $0.29(0.11,0.78)$ & $5 / 247$ & $16 / 231$ & 26.98 \\
\hline \multicolumn{3}{|c|}{ Subtotal $(R=0.0 \%, p=0.718)$} & & & $0.23(0.11,0.48)$ & $9 / 752$ & $31 / 565$ & 50.23 \\
\hline & & & & & & \\
\hline \multicolumn{3}{|c|}{$\begin{array}{l}\text { Not subtantial } \\
\text { Gore REDUCE } 2017\end{array}$} & & & $0.28(0.03,2.99)$ & $1 / 77$ & $2 / 43$ & 4.68 \\
\hline RESPECT & 2017 & & & & $1.07(0.50,2.30)$ & $13 / 247$ & $12 / 244$ & 45.08 \\
\hline \multicolumn{3}{|c|}{ Subtotal $\left(R^{2}=10.5 \%, p=0.291\right)$} & & & $0.94(0.46,1.95)$ & $14 / 324$ & $14 / 287$ & 49.77 \\
\hline \multicolumn{3}{|c|}{ Heterogeneity between groups: $p=0.008$} & & & & & & \\
\hline \multicolumn{3}{|c|}{ Overall $\left(R^{2}=55.0 \%, p=0.064\right)$} & & & $0.47(0.28,0.78)$ & $23 / 1,076$ & $45 / 852$ & 100.00 \\
\hline & & 0.20 .5 & 2 & 5 & & & & \\
\hline b & & Device closure better & & edica & erapy better & & & \\
\hline
\end{tabular}

Fig. 4. Subgroup analyses of treatment effect in the prevention of stroke recurrence. a Age. Younger versus older age groups were defined according to the threshold of 45 years in the RESPECT and
REDUCE trials and 44.6 years in the CLOSE study. b Inter-atrial shunt size. Sub-groups were moderate to substantial versus small shunt size in the REDUCE trial.

(For figure $4 c$ see next page.) of the patient's underlying conditions by both a neurologist and cardiologist is the key to plan the management and identify the candidates to the endovascular procedure. First, truly cryptogenic ischemic strokes should be recognized by ruling out alternative etiologies, including small-vessel disease, subclinical arrhythmias, aortic arch atheroma, intracranial stenosis, and hypercoagulable states. Second, the relatedness of the PFO to the index event should be considered, since cryptogenic strokes in patients with PFO may be also due to PFO-unrelated mechanisms [33]: the MT may presumably have protective effects toward recurrence of both PFO-related and unrelated strokes, while endovascular closure can protect only against the former. In this respect, the Risk of Paradoxical Embolism model combines clinical and neuroimaging findings to segregate patients with pathogenic rath- 


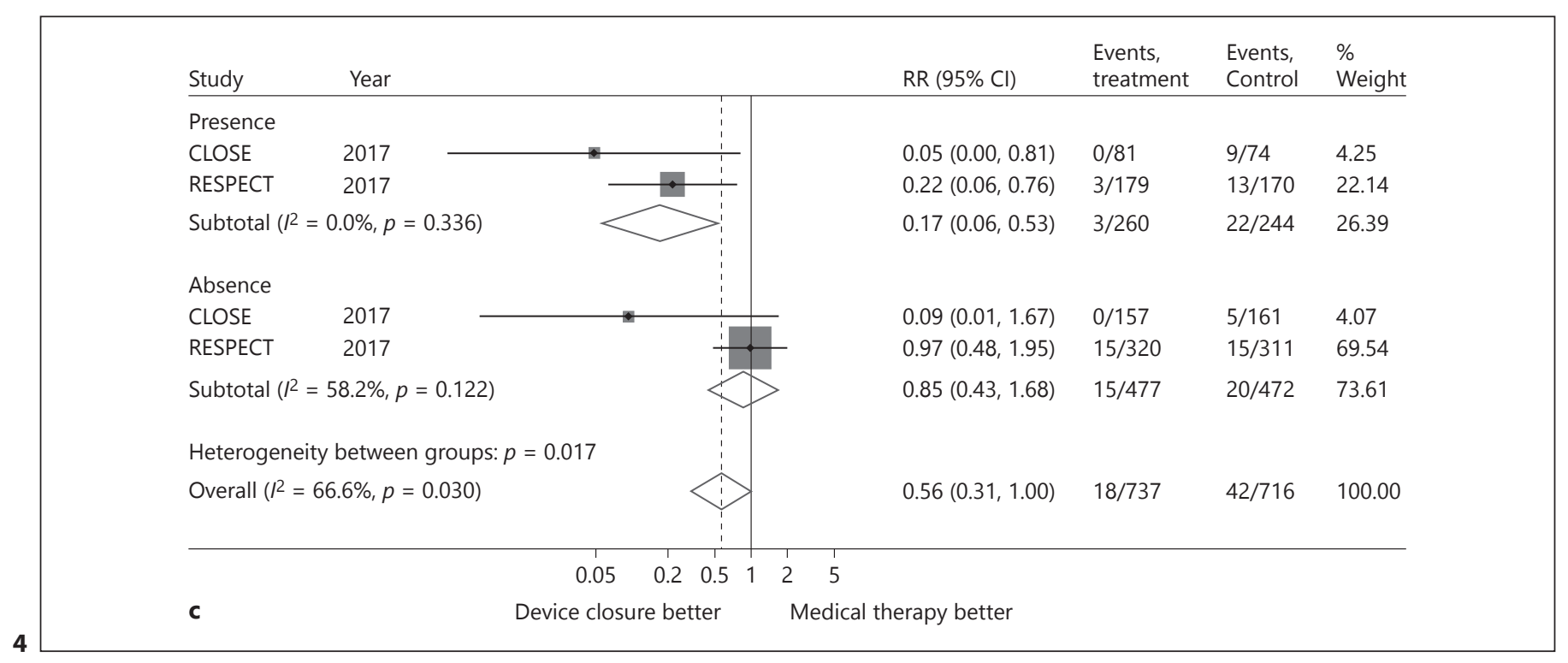

er than incidental PFO [34]: the PFO-attributable fraction of strokes ranges from less than $5 \%$ in old patients with deep infarcts and multiple conventional vascular risk factors to near $90 \%$ in younger patients without risk factors and with superficial infarcts. Finally, patients with presumably pathogenic $\mathrm{PFO}$ and who are likely to receive a greater benefit from the DC than from the MT alone should be identified. Bearing in mind all these issues, the support for the endovascular PFO closure provided by the most recent trials could be, at least partly, explained by the stringent selection and baseline characteristics of the participants. For example, small artery disease [30$32]$ and uncontrolled vascular risk factors [30, 32] were exclusion study criteria, and only patients with $\mathrm{PFO}$ and large shunt and/or ASA were included [31].

One question left unanswered concerns the role of oral anticoagulation compared to the DC, particularly for novel oral anticoagulants, factor Xa inhibitors and direct thrombin inhibitors, which have effective venous thrombosis prevention, less bleeding risk, and greater convenience of use than warfarin [35]. No randomized controlled trial has directly and adequately compared anticoagulant strategy versus PFO closure. In the CLOSURE I trial, there was no evidence of outcome interaction with anti-thrombotic treatment, namely, aspirin, warfarin, or aspirin plus warfarin [28]. In the RESPECT study, potential heterogeneity of the treatment effect was noted, with a suggestion of greater stroke risk reduction with the DC than with the MT among patients randomly assigned to anti-platelets rather than warfarin [30]. A signal pointing toward superiority of oral anticoagulation over anti- platelet treatment emerged by comparing the 2 medical arms in the CLOSE trial [31], but statistical significance was not evaluated since the study was underpowered for this analysis, and the wide confidence intervals of the estimates prevented any conclusion. Noteworthy, when life-long anticoagulation is clearly indicated, like in patients with high risk thrombophilia or unprovoked/recurrent deep vein thrombosis [36], it is not known whether the DC may offer additional benefit, although the existing evidence for any clinical advantage is limited.

The safety of the DC was comparable to the MT with respect to the overall risk of SAEs, major bleeding complications and all-cause mortality. Conversely, it is noteworthy that a higher rate of new-onset AF and flutter was observed in the device arm than in the MT group: overall, $\mathrm{AF}$ has been reported in $4.1 \%$ of the patients undergoing the percutaneous closure and in $0.7 \%$ of the patients randomized to the medical care. Post-implant AF usually occurred early after the PFO closure, with most of the cases detected within 30 days, and this is a finding that suggests that the procedure itself induces the tachyarrhythmia. More than one-half of all post-closure AFs were transient and resolved spontaneously or after conversion within the first few weeks; only a minority progressed to permanent rhythm disturbance. The exact clinical relevance of closure-related AF, including the risk of stroke, has not been however fully determined and requires further investigation. Taken together, these findings emphasize the need for a close initial monitoring of the cardiac rhythm and appropriate management of documented arrhythmias in patients undergoing the PFO closure. 
Device implantation was successful, with no procedural complications, in $96 \%$ and effective closure, with no or minimal residual shunt, was achieved by $91 \%$ of the endovascularly treated patients; in accordance with the results of a previous network meta-analysis [37], the lowest rates were associated with the umbrella occluder (STARFlex septal closure system), which has been discontinued and no longer manufactured.

This systematic review provides useful insights into the management of PFO in patients with history of cerebral ischemia by analyzing the most recently available findings, [30-32] and updates the previous meta-analyses that have included only the initial trials and yielded conflicting conclusions depending on methodology [38, 39]. Remarkably, the efficacy sub-analyses according to individual features could have clinical relevance and practical implications to identify the patients most likely to benefit from the endovascular approach. In addition, risk estimates were synthetized both as RRs derived from the time-in-point analysis, which can be more realistic but less accurate in the presence of time-based outcomes, and HRs obtained from the time-to-event analysis, which can account for differences in follow-up intervals, drop-out rates, and participants lost to follow-up. Nonetheless, the results of the meta-analysis inherited the limitations of the included studies. The opportunity to have PFO closure performed outside the trial, and the preferential treatment with off-label DC of patients more likely to have PFOrelated vascular events, slowed recruitment and could have excluded high-risk PFO patients. The cross-over between arms, the relatively high number of patients lost to follow-up compared to the events, and the unbalanced dropout rates between the DC and MT groups could have introduced possible sources of biases [29-32]. In this re- spect, the use of individual-participant data instead of study-level aggregate results would have allowed covariates adjustment, handling of missing data, and assessment of variations in treatment effect with variations in patient characteristics. Finally, although device implantation is essentially a permanent intervention, the average followup ranged from 2 to 5.9 years: this meta-analysis cannot provide information about the long-term potential for $\mathrm{cu}$ mulative onset of device-related complications.

In conclusion, the potential benefit from closure is determined on the basis of individual factors, clinical presentation, and PFO characteristics. Current guidelines advise against the routine use of DC among patients with cryptogenic stroke and PFO outside a research setting, and they support it only in "rare circumstances," such as recurrent strokes despite adequate MT or evidence of deep vein thrombosis at high risk to recur [40-42]. Notably, these recommendations are based on the null results of the randomized controlled studies available before September 2017 [28, 29, 43]; the newly available data can contribute to better define the boundaries that support the procedure, inform the risk-benefit discussion, and will likely promote changes in guidance in the near future.

\section{Disclosure Statement}

The authors declare that they have no conflicts of interest to disclose.

\section{Funding Source}

This study received no funding.

\section{References}

1 Feigin VL, Norrving B, Mensah GA: Global burden of stroke. Circ Res 2017;120:439448.

2 Lattanzi S, Silvestrini M, Provinciali L: Elevated blood pressure in the acute phase of stroke and the role of Angiotensin receptor blockers. Int J Hypertens 2013;2013:941783.

-3 Saver JL: Clinical practice. Cryptogenic stroke. N Engl J Med 2016:374:2065-2074.

4 Lattanzi S, Cagnetti C, Pulcini A, et al: The Pwave terminal force in embolic strokes of undetermined source. J Neurol Sci 2017;375: 175-178.

5 Hagen PT, Scholz DG, Edwards WD: Incidence and size of patent foramen ovale during the first 10 decades of life: an autopsy study of
965 normal hearts. Mayo Clin Proc 1984;59: 17-20.

6 Homma S, Sacco RL: Patent foramen ovale and stroke. Circulation 2005;112:10631072.

7 Lechat P, Mas JL, Lascault G, et al: Prevalence of patent foramen ovale in patients with stroke. N Engl J Med 1988;318:1148-1152.

8 Alsheikh-Ali AA, Thaler DE, Kent DM: Patent foramen ovale in cryptogenic stroke: incidental or pathogenic? Stroke 2009;40:23492355.

-9 Overell JR, Bone I, Lees KR: Interatrial septal abnormalities and stroke: a meta-analysis of case-control studies. Neurology 2000;55: 1172-1179.
10 Cabanes L, Mas JL, Cohen A, et al: Atrial septal aneurysm and patent foramen ovale as risk factors for cryptogenic stroke in patients less than 55 years of age. A study using transesophageal echocardiography. Stroke 1993;24:1865-1873.

11 Maron BA, Shekar PS, Goldhaber SZ: Paradoxical embolism. Circulation 2010;122: 1968-1972.

12 Berthet K, Lavergne T, Cohen A, et al: Significant association of atrial vulnerability with atrial septal abnormalities in young patients with ischemic stroke of unknown cause. Stroke 2000;31:398-403.

13 Silver MD, Dorsey JS: Aneurysms of the septum primum in adults. Arch Pathol Lab Med 1978;102:62-65. 
14 Schneider B, Hanrath P, Vogel P, Meinertz T: Improved morphologic characterization of atrial septal aneurysm by transesophageal echocardiography: relation to cerebrovascular events. J Am Coll Cardiol 1990;16:1000-1009.

-15 Di Tullio MR, Homma S: Patent foramen ovale and stroke: what should be done? Curr Opin Hematol 2009;16:391-396.

16 Moher D, Liberati A, Tetzlaff J, Altman DG; PRISMA Group: Preferred reporting items for systematic reviews and meta-analyses: the PRISMA statement. PLoS Med 2009; 6:e1000097.

17 Higgins JP, Green S: Cochrane Handbook for Systematic Reviews of Interventions Version 5.1.0 (updated March 2011). The Cochrane Collaboration, 2011. http://handbook-5-1. cochrane.org/(accessed December 2017).

- 18 Higgins JP, Thompson SG, Deeks JJ, Altman DG: Measuring inconsistency in meta-analyses. BMJ 2003;327:557-560.

19 Higgins JP, Thompson SG: Quantifying heterogeneity in a meta-analysis. Stat Med 2002; 21:1539-1558.

20 Lattanzi S, Cagnetti C, Provinciali L, Silvestrini M: How should we lower blood pressure after cerebral hemorrhage? A systematic review and meta-analysis. Cerebrovasc Dis 2017;43:207-213

21 Lattanzi S, Cagnetti C, Foschi N, Provinciali L, Silvestrini M: Brivaracetam add-on for refractory focal epilepsy: a systematic review and meta-analysis. Neurology 2016;86:1344-1352.

-22 Lattanzi S, Cagnetti C, Danni M, Provinciali L, Silvestrini M: Oral and intravenous steroids for multiple sclerosis relapse: a systematic review and meta-analysis. J Neurol 2017;264: $1697-1704$

23 Lattanzi S, Grillo E, Brigo F, Silvestrini M: Efficacy and safety of perampanel in Parkinson's disease. A systematic review with meta-analysis. J Neurol 2017, DOI: 10.1007/s00415017-8681-y.

24 Landzberg MJ, Khairy P: Indications for the closure of patent foramen ovale. Heart 2004; 90:219-224.

25 Steiner MM, Di Tullio MR, Rundek T, et al: Patent foramen ovale size and embolic brain imaging findings among patients with ischemic stroke. Stroke 1998;29:944-948.

26 The Effect of Device Closure of Patent Foramen Ovale in Elderly Patients with Cryptogenic Stoke/TCI (CryptoCard). https://clinicaltrials.gov/ct2/NCT01018355

27 Device Closure versus Medical Therapy for Cryptogenic Stroke Patients with High-Risk Patent Foramen Ovale (DEFENSE-PFO). https://clinicaltrials.gov/ct2/NCT01550588

28 Furlan AJ, Reisman M, Massaro J, et al; CLO SURE I Investigators: Closure or medical therapy for cryptogenic stroke with patent foramen ovale. N Engl J Med 2012;366:991-999.

29 Meier B, Kalesan B, Mattle HP, et al; PC Trial Investigators: Percutaneous closure of patent foramen ovale in cryptogenic embolism. N Engl J Med 2013;368:1083-1091.

30 Saver JL, Carroll JD, Thaler DE, et al; RESPECT Investigators: Long-term outcomes of patent foramen ovale closure or medical therapy after stroke. N Engl J Med 2017;377:10221032.

-31 Mas JL, Derumeaux G, Guillon B, et al; CLOSE Investigators: Patent foramen ovale closure or anticoagulation vs. antiplatelets after stroke. N Engl J Med 2017;377:1011-1021.

32 Søndergaard L, Kasner SE, Rhodes JF, et al; Gore REDUCE Clinical Study Investigators: Patent foramen ovale closure or antiplatelet therapy for cryptogenic stroke. N Engl J Med 2017;377:1033-1042.

33 Alsheikh-Ali AA, Thaler DE, Kent DM: Patent foramen ovale in cryptogenic stroke: incidental or pathogenic? Stroke 2009;40:23492355.

34 Kent DM, Ruthazer R, Weimar C, et al: An index to identify stroke-related vs incidental patent foramen ovale in cryptogenic stroke. Neurology 2013;81:619-625.

35 Mekaj YH, Mekaj AY, Duci SB, Miftari EI: New oral anticoagulants: their advantages and disadvantages compared with vitamin $\mathrm{K}$ antagonists in the prevention and treatment of patients with thromboembolic events. Ther Clin Risk Manag 2015;11:967-977.

36 Kearon C, Akl EA, Ornelas J, et al: Antithrombotic therapy for VTE disease: CHEST guide- line and expert panel report. Chest 2016;149: 315-352.

37 Stortecky S, da Costa BR, Mattle HP, et al: Percutaneous closure of patent foramen ovale in patients with cryptogenic embolism: a network meta-analysis. Eur Heart J 2015;36:120128

38 Rengifo-Moreno P, Palacios IF, Junpaparp P, Witzke CF, Morris DL, Romero-Corral A: Patent foramen ovale transcatheter closure vs. medical therapy on recurrent vascular events: a systematic review and meta-analysis of randomized controlled trials. Eur Heart J 2013; 34:3342-3352.

39 Li J, Liu J, Liu M, et al: Closure versus medical therapy for preventing recurrent stroke in patients with patent foramen ovale and a history of cryptogenic stroke or transient ischemic attack. Cochrane Database Syst Rev 2015;9: CD009938.

40 Messé SR, Gronseth G, Kent DM, et al: Practice advisory: recurrent stroke with patent foramen ovale (update of practice parameter): report of the guideline development, dissemination, and implementation subcommittee of the American academy of neurology. Neurology 2016;87:815-821.

41 Kernan WN, Ovbiagele B, Black HR, et al; American Heart Association Stroke Council, Council on Cardiovascular and Stroke Nursing, Council on Clinical Cardiology, and Council on Peripheral Vascular Disease: Guidelines for the prevention of stroke in patients with stroke and transient ischemic attack: a guideline for healthcare professionals from the American Heart Association/American Stroke Association. Stroke 2014;45: 2160-2236.

42 European Stroke Organisation (ESO) Executive Committee; ESO Writing Committee: Guidelines for management of ischaemic stroke and transient ischaemic attack 2008 Cerebrovasc Dis 2008;25:457-507.

43 Carroll JD, Saver JL, Thaler DE, et al; RESPECT Investigators: Closure of patent foramen ovale versus medical therapy after cryptogenic stroke. N Engl J Med 2013;368:10921100 . 